\title{
Highly Efficient Silver Catalyst Supported by a Spherical Covalent Organic Framework for the Continuous Reduction of 4-Nitrophenol
}

\author{
Ning Wang,* Fushuai Wang, Fei Pan, Shunyang Yu, and Dawei Pan*
}

Cite This: ACS Appl. Mater. Interfaces 2021, 13, 3209-3220

Read Online

ACCESS | Lلll Metrics \& More | 回 Article Recommendations ｜ st Supporting Information
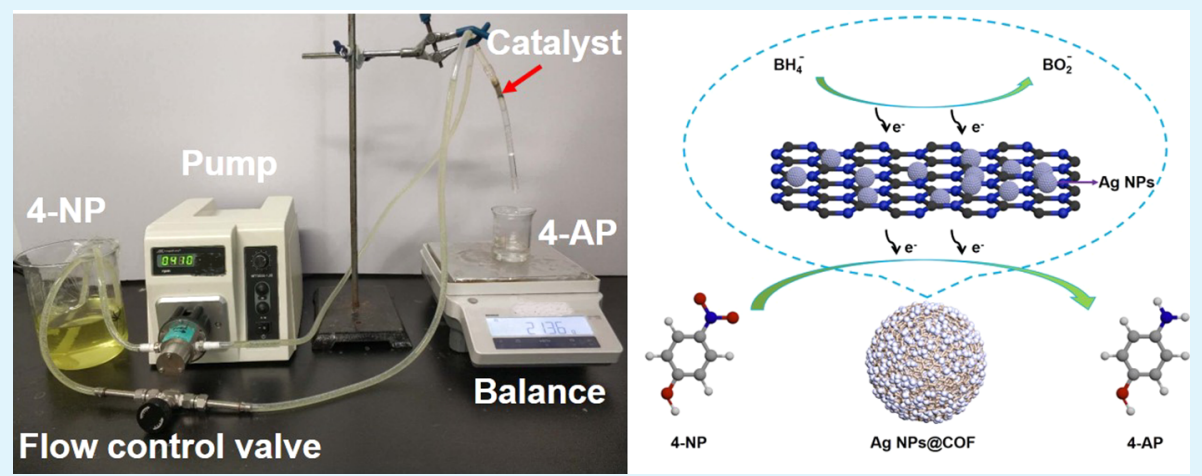

ABSTRACT: Developing new materials and novel technologies for the highly efficient treatment of toxic organic pollutants is highly desirable. Chemical reduction based on heterogeneous substrate/noble metal catalysts and the reducing agent $\mathrm{NaBH}_{4}$ has become an effective method in recent years. Here, a spherical covalent organic framework (SCOF) was designed to provide basic sites for Ag ions, by which small Ag NPs were immobilized on the SCOF to form Ag NPs@SCOF microspheres. The prepared microspheres exhibited a high catalytic reduction ability toward 4-nitrophenol (4-NP). An optimized permeation flux of $2000 \mathrm{~L}^{-2}$ $\mathrm{h}^{-1}(\mathrm{LMH})$ and a more than 99\% 4-NP reduction efficiency were obtained with flow-through experiments, which are far better than the reported results (below $200 \mathrm{LMH}$ ). Moreover, the microspheres could maintain stable catalytic performance under a continuous flow-through process. Our work provides an efficient material and technology that can be applied to easily treat toxic organic pollutants.

KEYWORDS: covalent organic framework, catalytic reduction, organic pollutants, flow-through, silver nanoparticles

\section{INTRODUCTION}

Noble metal nanoparticle-based heterogeneous catalysts have attracted considerable attention in recent years due to their potential outstanding catalytic activities toward toxic organic pollutants. $^{1-16}$ Semiconductor material substrates, such as porous carbon, ${ }^{17,18}$ graphene oxide (GO), ${ }^{19-22}$ graphitic carbon nitride $\left(\mathrm{g}-\mathrm{C}_{3} \mathrm{~N}_{4}\right),{ }^{23-25}$ molybdenum disulfide $\left(\mathrm{MoS}_{2}\right){ }^{26}$ metal organic frameworks (MOFs), ${ }^{27-32}$ and covalent organic frameworks (COFs), ${ }^{33,34}$ can not only immobilize and limit the aggregation of tiny noble metal nanoparticles but also provide abundant electrons to noble metal nanoparticles, thus effectively strengthening the electron transfer of noble metal nanoparticles from the reduction agents such as $\mathrm{NaBH}_{4}$ to electron acceptor toxic organic pollutants to obtain nontoxic and beneficial forms. ${ }^{35,36}$ Compared with other substrates, COF materials have the characteristics of large specific surface areas (more than $300 \mathrm{~m}^{2} \mathrm{~g}^{-1}$ ) and chemical stability and are more suitable substrates for supporting noble metal nanoparticles. ${ }^{37-40}$ In addition, the chemical structure of a COF can be tailored through the introduction of functionalized groups such as thioether groups and nitrogen groups during the synthesis and post modification processes, which can impart strong interfacial interactions between noble metal nanoparticles and the COF skeleton, facilitating enhanced catalytic performance toward toxic organic pollutants. ${ }^{41,42}$

The separation and reuse of noble metal nanoparticle-based heterogeneous catalysts is the key point affecting their application. Currently, due to its large surface area and low density, COF materials are difficult to sink in mixtures, even under high-speed centrifugation, which increases the cost of toxic organic pollutant treatment. To overcome these drawbacks, magnetic materials, such as $\mathrm{Fe}_{3} \mathrm{O}_{4}{ }^{43-46}$ and iron-rich materials, ${ }^{47-49}$ were used as substrates. $\mathrm{Xu}$ et al. reported the

Received: November 16, 2020

Accepted: December 28, 2020

Published: January 6, 2021 
fabrication of $\mathrm{Fe}_{3} \mathrm{O}_{4}$ supported $\mathrm{COF} / \mathrm{Au}$ composites for the catalytic reduction of 4-nitrophenol (4-NP) ${ }^{50}$ After recycling 5 times, the catalytic activity was almost unaltered, exhibiting good stability. Nevertheless, treatment is still expensive because abundant equipment is involved. ${ }^{51}$ In addition, catalyst separation from the mixture and reuse process would also reduce the treatment efficiency. Therefore, developing a novel technology for the highly efficient treatment of toxic organic pollutants is highly desirable.

Membrane separation is an important research field of separation and purification technology due to its advantages of efficient and continuous treatment of organic pollutants. ${ }^{52}$ Recently, catalytic membranes with membrane supporting noble metal nanoparticles have drawn great attention due to their functionalization and treatment of toxic organic pollutants in addition to separation. ${ }^{53-55}$ For example, Dong et al. reported the fabrication of polysiloxane/COF/Pd NPs flat sheet membranes and use them to continuously treat organic pollutant chlorobenzenes. ${ }^{56}$ A catalytic reduction efficiency of $98 \%$ was achieved, while the separation efficiency was unsatisfactory due to the lower loading of noble metal nanoparticles supported on the surface of these flat sheet membranes derived from the restriction of the membrane surface area. Thus, the efficiency of the separation system is limited.

Compared with COF-based flat sheet membranes, these membranes fabricated by the stacking of COF particles have more advantages, such as loose structures and large specific surface areas for the effective loading of noble metal nanoparticles. Among these COF particles with various structures (including lamella and dendritic structures), spherical COF particles have larger surface areas to provide more active sites for electron transfer and higher porosity for the fast pass through the feed solution. ${ }^{57,58}$ Furthermore, SCOF particles with good monodispersity are facile uniformly supporting the noble nanoparticles, facilitating improving the stability of the prepared catalyst. ${ }^{59,60}$ Here, a SCOF with a specific surface area of more than $500 \mathrm{~m}^{2} \mathrm{~g}^{-1}$ and an average diameter of approximately $2 \mu \mathrm{m}$ was synthesized and first used as a substrate for supporting silver nanoparticles (Ag NPs). Microsized SCOF was selected due to their stability in the continuous flow process, which is no easy leach out. Compared with other noble metals, such as Au NPs and Pt NPs, Ag NPs have been widely used because of their excellent electron transfer ability and high-cost effectiveness. ${ }^{61-63}$ Phenolic compounds are considered hazardous pollutants by the U.S. EPA, which would affect the environment. ${ }^{64}$ Catalytic reduction of 4-NP to low toxic amines 4-aminophenol (4$\mathrm{AP}$ ) is a green approach for environmental remediation. Furthermore, 4-AP can be reused in the chemical industry such as pharmaceuticals, pesticides, and urethane industries. ${ }^{65,66}$ Therefore, the catalytic performance toward 4-NP was systematically evaluated through the static and dynamic process. Stability and recyclability were investigated by testing the release of Ag NPs and a continuous catalytic performance during the flow-through process. To the best of our knowledge, few studies have explored fast treatment technology using the spherical COF materials and flow-through technology toward nitrophenol derivatives, providing a potential application for highly efficient and sustainable treatment.

\section{MATERIALS AND METHODS}

Materials and Chemicals. 1,3,5-Tris(4-aminophenyl) benzene (TPB) and 2,5-divinylterephthalaldehyde (DVA) with purities above 98.0\% were purchased from Jilin Chinese Academy of SciencesYanshen Technology Co., China. Other reagents and chemicals including acetonitrile (ACN, $\geq 98.0 \%)$, 4-nitrophenol (4-NP, $\geq$ $98.0 \%$ ), dopamine hydrochloride (DA, $\geq 98.0 \%$ ), and sodium borohydride $\left(\mathrm{NaBH}_{4}, \geq 99.0 \%\right)$ were obtained from Sinopharm Chemical Reagent Co. Ltd., China. All reagents were used without any further purification. The morphology, structure, and composition of the samples were characterized by scanning electron microscopy (SEM, Jeol S4800) and transmission electron microscopy (TEM, JEM

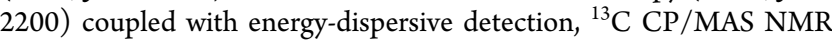
(JNM-ECZ600R), X-ray photoelectron spectroscopy (XPS, Thermo Fisher Scientific, Thermo EscaLab 250Xi), surface area and pore analysis (Micromeritics ASAP 2020), thermogravimetric analysis (TGA, Mettler 5MP/PF7548/MET/400W instrument), and X-ray diffraction (XRD, Bruker D8-Advantage powder diffractometer). The concentration of Ag NPs was measured by inductively coupled plasma mass spectrometry (ICP-MS, PerkinElmer ELAN DRC II). The catalytic activity was evaluated by a UV-vis spectrometer (PERSEE UT 1810).

Synthesis of the SCOF. TPB $(0.04 \mathrm{mmol})$ and DVA $(0.06$ mmol) were mixed with $5 \mathrm{~mL} \mathrm{CAN} \mathrm{and} \mathrm{sonicated} \mathrm{for} 2 \mathrm{~min}$. Afterward, acetic acid $(12 \mathrm{M}, 0.4 \mathrm{~mL})$ was added to the mixture, which was incubated for 3 days at room temperature. ${ }^{60}$ Then, the resulting yellow precipitate was collected through high-speed centrifugation, followed by washing with anhydrous acetone and anhydrous tetrahydrofuran three times. The product was dried under high vacuum at $60{ }^{\circ} \mathrm{C}$ for $24 \mathrm{~h}$.

Fabrication of Ag NPs@SCOF. SCOF (0.5 g) was dispersed in $250 \mathrm{~mL}$ of DI water and then $\mathrm{AgNO}_{3}(0.1 \mathrm{~g})$ was added to the mixture. After reaction for $3 \mathrm{~h}, \mathrm{NaBH}_{4}(15 \mathrm{~mL}, 3 \mathrm{mM})$ was added dropwise. Then, the mixture was stirred for $12 \mathrm{~h}$ in the dark. After washing three times with DI water and collecting by centrifugation, the Ag NPs@SCOF product was obtained after drying under a high vacuum at $60{ }^{\circ} \mathrm{C}$ for $24 \mathrm{~h}$. The content of the Ag NPs with a loading of 0.95 wt $\%$ was determined by ICP-MS.

Catalytic Experiment. Both static experiments and flow-through experiments were applied to evaluate the catalytic performance of the prepared Ag NPs@SCOF catalyst toward 4-NP. For static experiments, 25 mg of Ag NPs@SCOF microspheres were typically added to $100 \mathrm{~mL}$ of an aqueous solution containing $15 \mathrm{mg} / \mathrm{L} 4-\mathrm{NP}$ and 0.2 $\mathrm{M} \mathrm{NaBH}_{4}$. The time-dependent concentration of the mixture was monitored by UV-vis absorption spectra. For the flow-through experiments, $50 \mathrm{mg}$ of Ag NPs@SCOF microspheres were packed into a $6 \mathrm{~mm}$ PVC tube with an effective length of $10 \mathrm{~mm}$ and blocked with degreasing cotton, as shown in Figure S1 of the Supporting Information (SI). Through the flow filtration system, a feed solution containing $15 \mathrm{mg} / \mathrm{L}$ 4-NP and $0.05 \mathrm{M} \mathrm{NaBH}_{4}$ was continuously catalytically reduced by the Ag NPs@SCOF microspheres.

The apparent reduction rate constant $k_{\text {app }}$ and reduction efficiency (E) were calculated with eqs 1 and 2, respectively.

$$
\begin{aligned}
& \ln \left(C_{t} / C_{0}\right)=-k_{\mathrm{app}} t \\
& E=\left(C_{0}-C_{t}\right) / C_{0}
\end{aligned}
$$

where $C_{t}$ and $C_{0}$ are the concentrations of the dyes at time $t$ and 0 , respectively, calculated from the calibration curves (Figure S2).

The flux $\left(H, \mathrm{~L} \mathrm{~m}^{-2} \mathrm{~h}^{-1}, \mathrm{LMH}\right)$ was calculated with eq 3 .

$$
H=\frac{V}{S \times t}
$$

where $V$ and $S$ are the cumulative permeability volume (L) and crosssection of the pipeline $\left(\mathrm{m}^{2}\right)$, respectively. 
Scheme 1. Fabrication Process of the Ag NPs@SCOF Catalyst Included a Condensation Reaction and the Chelation and Reduction of Ag Ions on the SCOF Substrate ${ }^{a}$
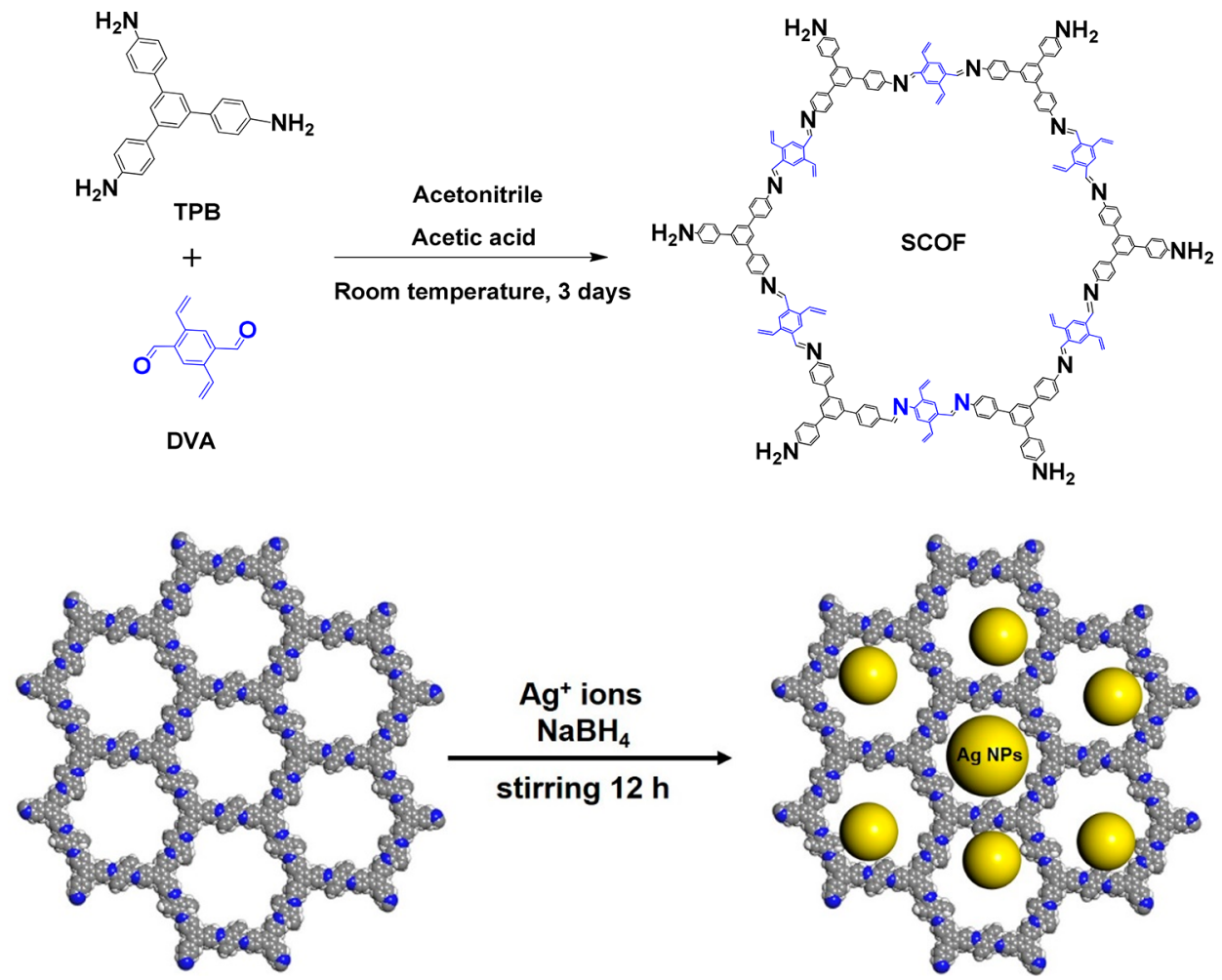

${ }^{a_{T}}$ The blue and yellow spheres represent $\mathrm{N}$ groups and Ag NPs, respectively.

a

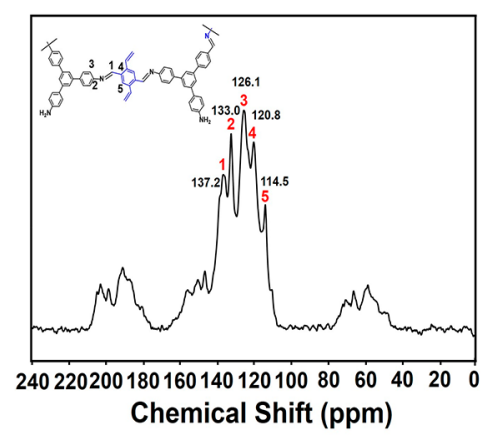

c

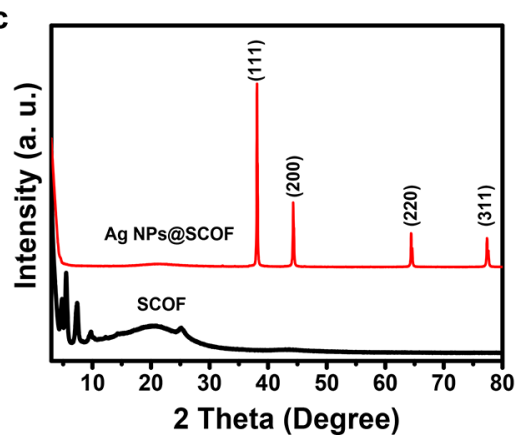

b

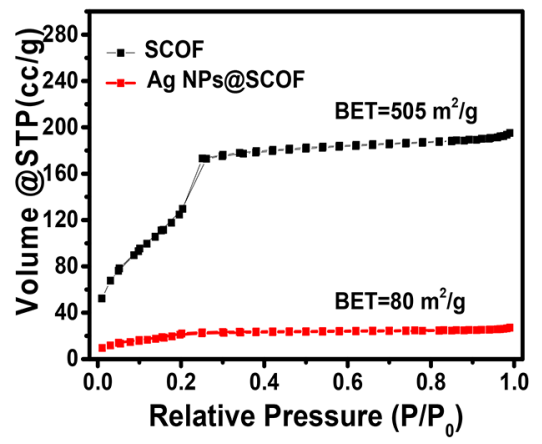

d

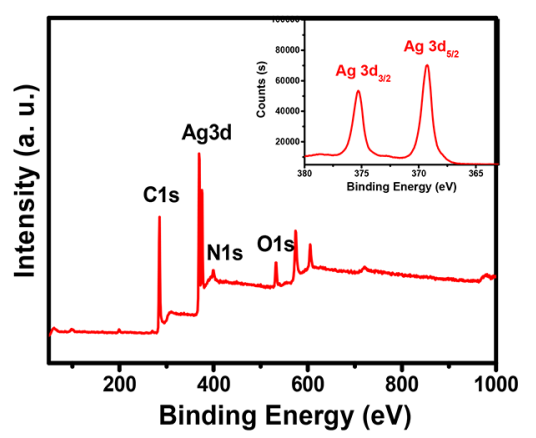

Figure 1. (a) ${ }^{13} \mathrm{C} \mathrm{CP} / \mathrm{MAS}$ NMR Spectrum of SCOF, (b) $\mathrm{N}_{2}$ adsorption-desorption isotherms of samples, and (c) XRD spectrum of Ag NPs@ SCOF. Inset: high-resolution XPS spectrum of Ag 3d and (d) XPS patterns of samples.

\section{RESULTS AND DISCUSSION}

Synthesis and Characterization of Ag NPs@SCOF. The SCOF was first synthesized through a condensation reaction with TPB as the organic linker and DVB as the knot at room temperature. After reacting for 3 days, the SCOF in the form of a yellow precipitate was obtained. ${ }^{60}$ Then, the dried SCOF was used as the substrate to fix the Ag NPs through the strong interfacial interaction between the abundant nitrogen func- 

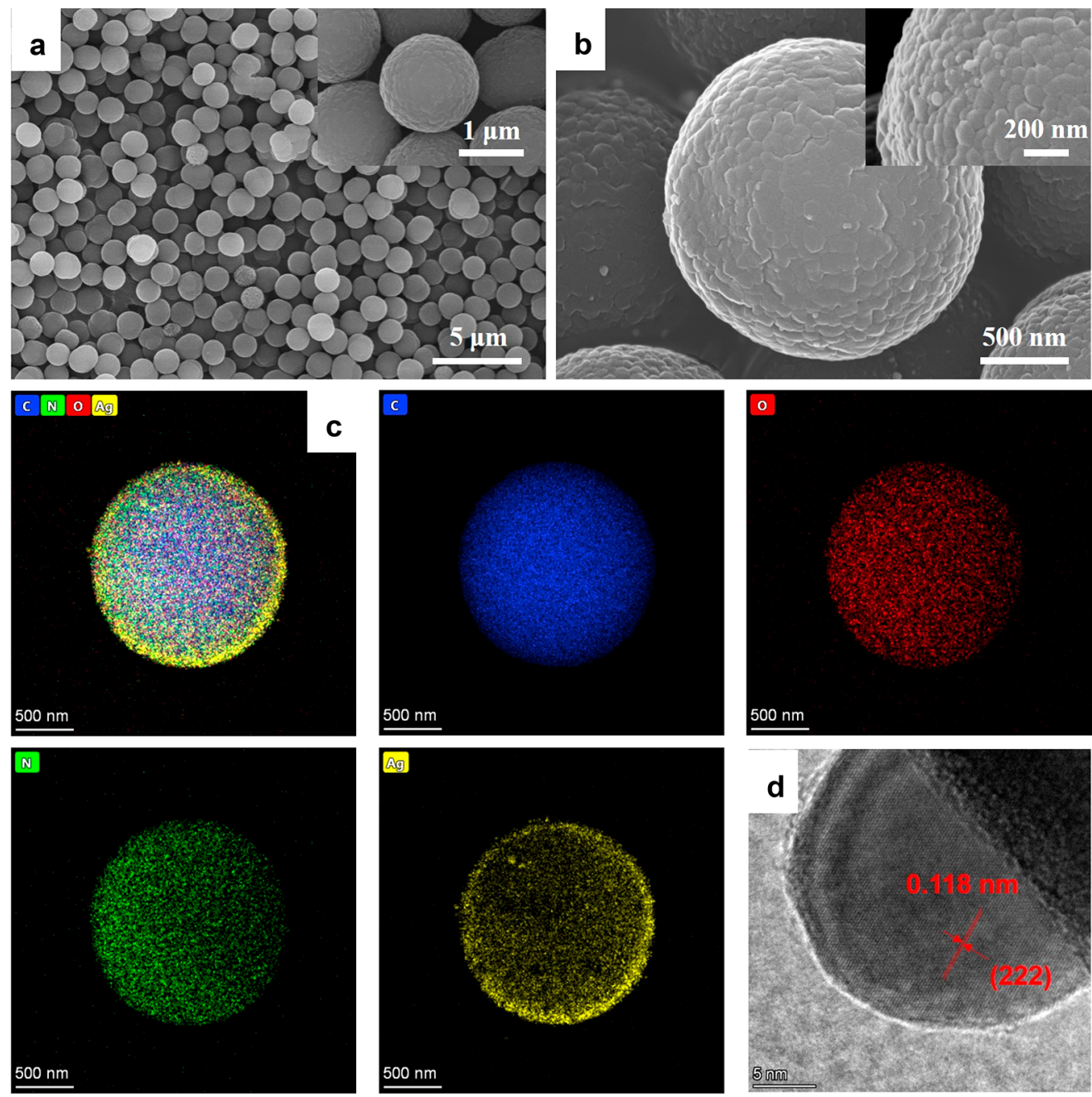

Figure 2. SEM images of the (a) the SCOF and (b) Ag NPs@SCOF with enlarged insets, (c) STEM-EDX elemental mapping images, and (d) high resolution TEM image of Ag NPs@SCOF.

tional groups of the SCOF and Ag NPs. Thus, Ag NPs@SCOF was fabricated, as shown in Scheme 1.

Morphological and Structural Studies. The synthesized SCOF was first characterized by solid-state ${ }^{13} \mathrm{C}$ crosspolarization magic angle spinning (CP-MAS) NMR spectroscopy. As shown in Figure 1a, five intense peaks between 100 and $180 \mathrm{ppm}$ were observed, and the chemical shift at 137.2 ppm indicated that condensation occurred between TPB and DVB. ${ }^{41,60}$ The porous structures of the SCOF and Ag NPs@ SCOF were investigated by measuring $\mathrm{N}_{2}$ sorption. As shown in Figure 1b, the BET specific surface area of the SCOF was calculated to be $505 \mathrm{~m}^{2} / \mathrm{g}$. This result indicated the large supported sites for loading Ag NPs. The value of Ag NPs@ SCOF decreased to $80 \mathrm{~m}^{2} / \mathrm{g}$ probably due to the deposition of nonporous Ag NPs altering the surface property of SCOF microsphere. ${ }^{50} \mathrm{XRD}$ was used to confirm the crystallinity of the SCOF and the loading of Ag NPs on the SCOF. As shown in Figure $1 \mathrm{c}$, three strong peaks at $2 \theta$ values of $4.7^{\circ}, 5.5^{\circ}$, and $7.3^{\circ}$, which is in accordance with the previous report, demonstrated the good crystallinity of the prepared SCOF. ${ }^{60}$ After loading of $\mathrm{Ag} \mathrm{NPs}$, four strong peaks at $2 \theta$ of $38.1^{\circ}$, $44.4^{\circ}, 64.5^{\circ}$, and $77.8^{\circ}$ can be observed, which agrees with the JCPDS card no. 04-0783, demonstrating the successful loading of Ag NPS on the SCOF surface. ${ }^{62}$ Although the content of Ag NPs is only 0.95 wt \% (quantified by ICP/MS), the intensity of peak is much higher than SCOF, reflecting the good coverage of Ag NPs on the surface of SCOF. ${ }^{67}$ XPS was used to provide information on the elemental composition and chemical states of the synthesized samples. As shown in Figure $1 \mathrm{~d}$, peaks corresponding to $\mathrm{C}, \mathrm{O}, \mathrm{N}$, and $\mathrm{Ag}$ can be observed, which is consistent with the formation of Ag NPs@SCOF microspheres. From the inset of Figure 1d, the binding energies at 375.3 and $369.3 \mathrm{eV}$ can be attributed to $\mathrm{Ag} 3 \mathrm{~d}_{3 / 2}$ and $\mathrm{Ag} 3 \mathrm{~d}_{5 / 2}$ of $\mathrm{Ag}(0)$, respectively, confirming the loading of $\mathrm{Ag}$ (0) NPs on the surface of the SCOF. ${ }^{63}$ Furthermore, the binding energy from pyrrolic $\mathrm{N}$ shifted from the 399.3 to 399.8 $\mathrm{eV}$ after loading of Ag NPs, suggesting the strong interactions between Ag NPs and the pyrrolic N atoms of SCOF (Figure S3). ${ }^{41}$

The morphologies of the SCOF and Ag NPs@SCOF were characterized by SEM and TEM. As shown in Figure 2a, the synthesized SCOF exhibited a spherical morphology with a smooth surface. The mean diameter was calculated to be $2 \mu \mathrm{m}$ from the inset of Figure 2a. The loading of Ag NPs had almost no effect on the surface morphology of the SCOF (Figure $2 b$ ). To confirm the successful loading of Ag NPs on the surface of SCOF, HR-TEM was used. As shown in Figure 2c, Ag NPs (yellow dots) were uniformly dispersed on the surface of SCOF. The average size of $\mathrm{Ag}$ NPs was calculated as approximately $20 \mathrm{~nm}$ (Figure S4). Although the size of $\mathrm{Ag}$ 
a
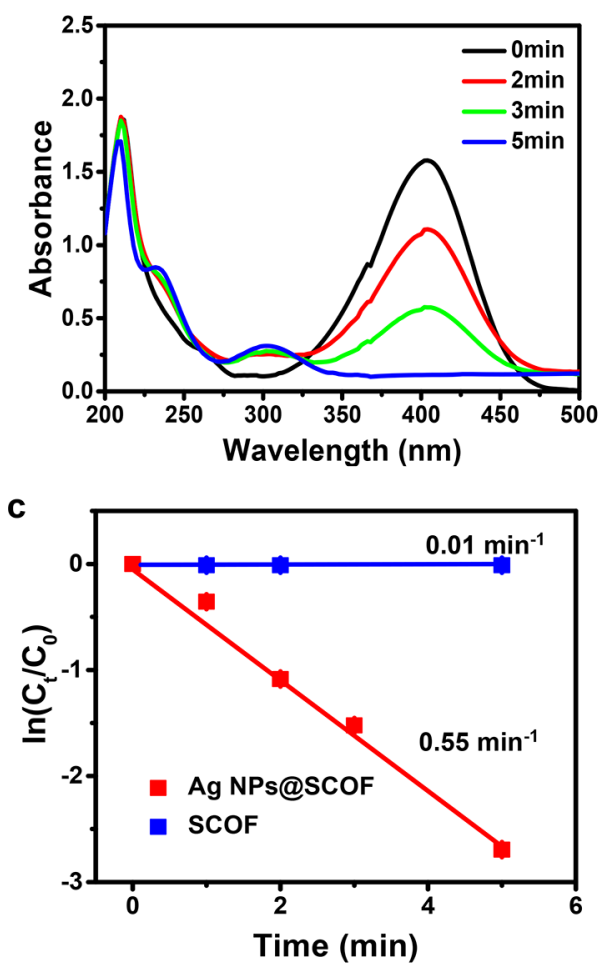

e

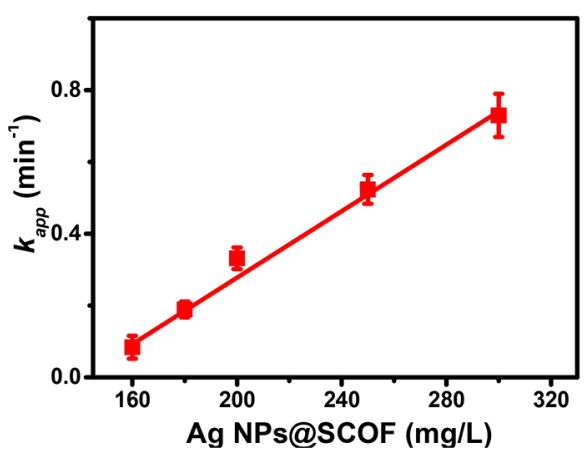

b

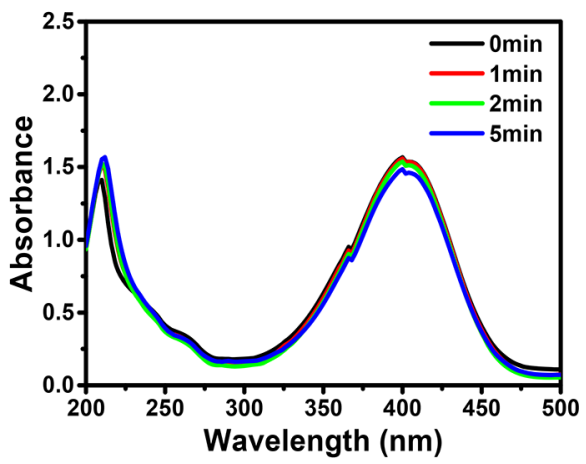

d

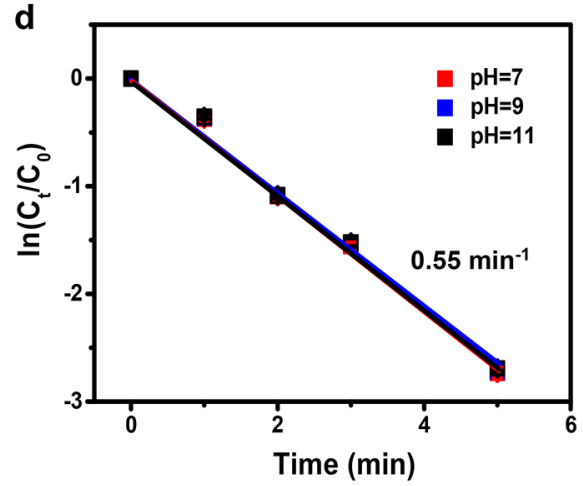

$\mathbf{f}$

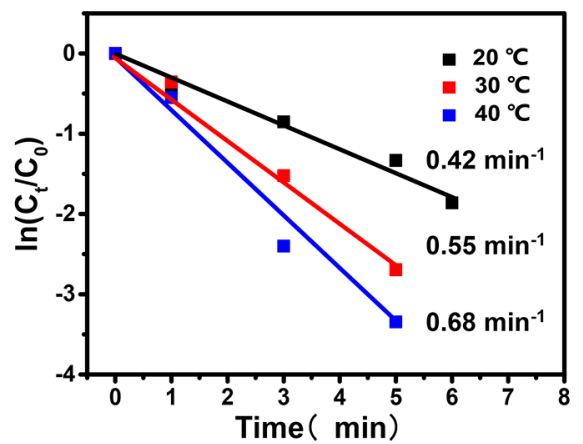

Figure 3. Time-resolved UV-vis spectra of 4-NP, (a) Ag NPs@SCOF and (b) the SCOF. (c) Plot of $\ln \left(C_{t} / C_{0}\right)$ versus reaction time for the catalytic reduction of 4-NP. The effect of (d) pH values, (e) Ag NPs@SCOF concentration, and (f) reaction temperature on the catalytic performance.

NPs is larger than the pore size of SCOF $(3 \mathrm{~nm})$, the Ag NPs can immobilize on the surface of SCOF due to the strong interfacial interactions between SCOF with abundant nitrogen and Ag NPs. ${ }^{41}$ The imaging of Ag NPs@SCOF (Figure 2d) exhibited the loading of Ag NPs and an interplanar spacing of $0.118 \mathrm{~nm}$, which was assigned to the (222) plane of the $\mathrm{Ag}$ crystal. $^{41}$ Considering that small Ag NPs are uniformly dispersed on the surface of the SCOF, the loaded Ag NPs can provide abundant active sites for the catalytic reduction of toxic organic pollutants.

Catalytic Properties of Ag NPs@SCOF Microspheres. The catalytic properties of the fabricated Ag NPs@SCOF microspheres were examined in the catalytic reduction of 4-NP in the presence of $\mathrm{NaBH}_{4}$. The reduction process was monitored by the change in UV-vis absorbance at wavelengths of 300 and $400 \mathrm{~nm} .{ }^{51}$ During the catalytic reduction process, the color of the 4-NP solution changed from greenyellow to colorless. Correspondingly, the characteristic absorbance of 4-NP at $400 \mathrm{~nm}$ rapidly decreased to 0 within $5 \mathrm{~min}$ and the characteristic absorbance of the reduced product
4-AP gradually increased at $300 \mathrm{~nm}$ (Figure 3a). To evaluate the catalytic performance of the fabricated Ag NPs@SCOF microspheres, the catalytic activity of the SCOF without $\mathrm{Ag}$ NPs was used as a control. As shown in Figure $3 b$, the characteristic absorbance of 4-NP at $400 \mathrm{~nm}$ was almost unaltered with prolonged reaction time, reflecting the effective catalytic performance of the Ag NPs@SCOF microspheres. Considering the excess concentration of $\mathrm{NaBH}_{4}$ existing in the catalytic system, kinetic eq 1 was used to evaluate the catalytic performance. As shown in Figure $3 c$, a good linear relationship between $\ln \left(C_{0} / C_{t}\right)$ and $t$ was exhibited by pseudo-first-order reaction kinetics. The slope $k_{\text {app }}$ of the Ag NPs@SCOF microspheres was calculated to be $0.55 \mathrm{~min}^{-1}$, which is much higher than that of 4-NP catalyzed by the SCOF $\left(0.01 \mathrm{~min}^{-1}\right)$. Furthermore, the influences of the $\mathrm{pH}$ value, the concentration of the catalyst, and reaction temperature were investigated. In this work, the concentration of $\mathrm{NaBH}_{4}$ is excessive, thus, the catalytic activity at different $\mathrm{pH}$ value can reflect the stability of the catalyst. As shown in Figure $3 \mathrm{~d}, k_{\text {app }}$ was maintained 0.55 $\min ^{-1}$ with increasing $\mathrm{pH}$ values from 7 to 11 . The value of $k_{\text {app }}$ 
a

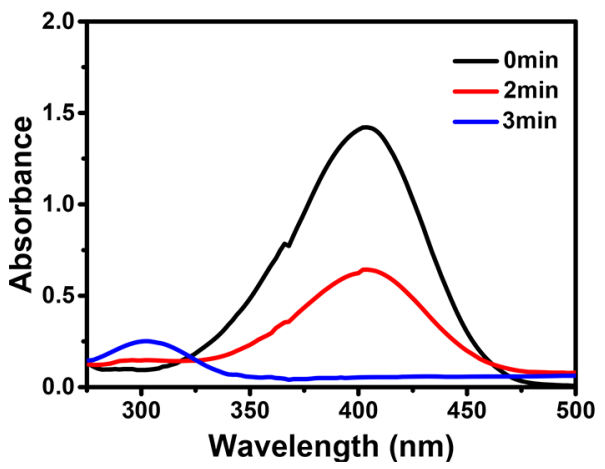

b

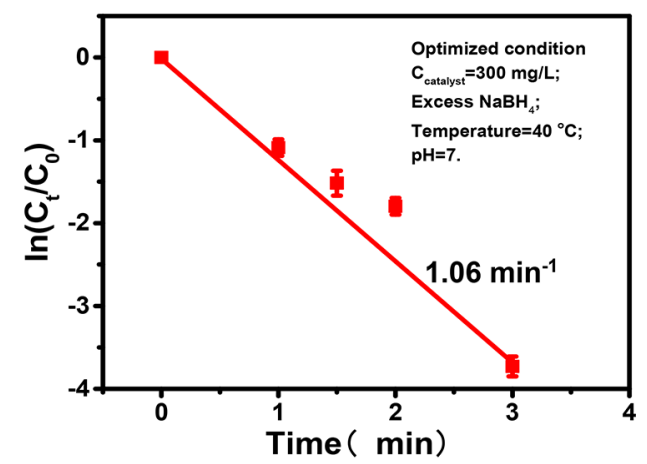

Figure 4. (a) Time-resolved UV-vis spectra of 4-NP solutions. (b) Plot of $\ln \left(C_{t} / C_{0}\right)$ versus reaction time for the catalytic reduction of 4-NP. The reaction conditions were as follows: $15 \mathrm{mg} \mathrm{L}^{-1} 4-\mathrm{NP}, 300 \mathrm{mg} \mathrm{L}{ }^{-1} \mathrm{Ag} \mathrm{NPs@SCOF,} \mathrm{pH} \mathrm{7,} \mathrm{and} \mathrm{temperature} \mathrm{of} 40{ }^{\circ} \mathrm{C}$.

Table 1. Comparison of the Catalytic Activities of Noble Metal-Based Heterogeneous Catalysts Reported Recently for 4-NP Reduction with $\mathrm{NaBH}_{4}$

\begin{tabular}{lcc}
\multicolumn{1}{c}{ catalyst } & $k_{\text {app }}\left(\mathrm{min}^{-1}\right)$ & TOF $\left(\mathrm{h}^{-1}\right)^{a}$ \\
$\mathrm{GO}-\mathrm{Au}$ & 0.12 & 42 \\
$\mathrm{Au} @ \mathrm{~g}-\mathrm{C}_{3} \mathrm{~N}_{4}$ & 0.90 & 12 \\
$\mathrm{Au} @ g-\mathrm{C}_{3} \mathrm{~N}_{4}$ & 0.36 & 87 \\
$\mathrm{SBA}-15 / \mathrm{PDA}_{0.6} / \mathrm{Ag}$ & 0.44 & \\
$\mathrm{HCB}-\mathrm{Au}$ & 0.05 & 56 \\
$\mathrm{Pt} @ \mathrm{COF}$ & - & \\
$\mathrm{Fe} \mathrm{O}_{4} @ \mathrm{PPy}-\mathrm{MAA} / \mathrm{Ag}$ & 0.17 & \\
$\mathrm{Au} @ \mathrm{PDA} @ \mathrm{Au}$ & 0.50 & \\
$\mathrm{Pd}-\mathrm{GA} / \mathrm{RGO}$ & 0.12 & \\
$\mathrm{MP} @$ Void-Pt@mSiO2 & 0.35 & \\
$\mathrm{Ag}-\mathrm{L} \mathrm{NPs} / \mathrm{LCG}$ & 0.37 & 18 \\
$\mathrm{Au} @ \mathrm{TR}-\mathrm{HCP}-\mathrm{TPMT}$ & 0.37 & 17 \\
$\mathrm{Ag} @ \mathrm{CMP}$ & 0.08 & 81 \\
$\mathrm{Au} @ S M t$ & 1.05 & \\
$\mathrm{Ag} \mathrm{NPs} @ S C O F$ & 1.06 &
\end{tabular}

Appl. Catal. B Environ., 2016 ${ }^{22}$

Appl. Catal. B Environ., 2019 ${ }^{24}$

Appl. Catal. B Environ., $2017^{25}$

ACS Appl. Mater. Inter., $\mathbf{2 0 1 8}^{68}$

Appl. Catal. B Environ., $2019^{69}$

J. Am. Chem. Soc., $2017^{70}$

Appl. Catal. B Environ., 2019 ${ }^{71}$

ACS Appl. Mater. Inter., $2017^{72}$

J. Hazard. Mater., $2017^{73}$

ACS Sustain. Chem. Eng., $\mathbf{2 0 1 8}^{74}$

ACS Sustain. Chem. Eng., $\mathbf{2 0 2 0}^{75}$

ACS Appl. Nano Mater., 2019 ${ }^{76}$

ACS Appl. Mater. Inter., 2017 77

App. Clay Sci., $2018^{78}$

this work

${ }^{a}$ The moles of 4-NP catalytically reduced per mole of $\mathrm{Ag}$ under the consumed time.

increased linearly with the concentration of Ag NPs@SCOF microsphere (Figure $3 \mathrm{e}$ ) and increased from $0.42 \mathrm{~min}^{-1}$ to $0.67 \mathrm{~min}^{-1}$ as the temperature increased from 20 to $40{ }^{\circ} \mathrm{C}$ (Figure $3 \mathrm{f}$ ). Thus, the reduction reaction can be finished within $3 \mathrm{~min}$ (Figure $4 \mathrm{a}$ ). The optimal $k_{\text {app }}$ value $\left(1.06 \mathrm{~min}^{-1}\right.$, Figure 4b) was obtained at $300 \mathrm{mg} \mathrm{L}^{-1} \mathrm{Ag}$ NPs@SCOF and a temperature of $40{ }^{\circ} \mathrm{C}$. Accordingly, the color of 4-NP vanished within $3 \mathrm{~min} .300 \mathrm{mg} \mathrm{L}^{-1}$ Ag NPs@SCOF was selected here due to the unaltered the turnover frequency (TOF, the moles of 4-NP catalytic reduced by per mole of $\mathrm{Ag}$ under the consumed time) as the concentration of Ag NPs@SCOF microsphere above $300 \mathrm{mg} \mathrm{L}^{-1}$ (Figure S5). TOF of the $\mathrm{Ag}$ NPs@SCOF microspheres was calculated to be $81.2 \mathrm{~h}^{-1}$, suggesting better catalytic activity toward 4-NP reduction than the noble metal-based heterogeneous catalysts recently reported (Table 1). For example, Cao et al. reported the fabrication of conjugated microporous polymer@Ag NPs nanocatalyst for the reduction of $4-\mathrm{NP} .^{77}$ Although the $\mathrm{Ag}$ particle size of $3.9 \mathrm{~nm}$ was achieved, the value of TOF only reached $17 \mathrm{~h}^{-1}$, which is much lower than our work. This result suggested the significant importance of SCOF as a substrate to fabricate catalyst.

Recyclability Examination. Five successive cycles were carried out. For one cycle, after finishing the catalytic reduction process, the catalyst was recovered by high speed centrifuga- tion and reused for the next cycle. As shown in Figure S6, the value of $k_{\text {app }}$ decreased by less than $10 \%$. The mass loss after separation from the mixture was determined. The mass loss percent of the Ag NPs@SCOF microspheres after 1, 3, and 5 cycles of the catalytic reduction of 4-NP decreased by 97.5 , 95.5, and $92.2 \mathrm{wt} \%$, respectively, agreeing with the decreased value of $k_{\text {app }}$. These results reflected the excellent stability of the Ag NPs@SCOF microspheres. Nevertheless, the catalyst was difficult to recover from the solution. Even high-speed centrifugation equipment was carried out, the mass loss of the catalyst is unbearable, which heavily increased the cost. Furthermore, although the catalytic reduction can be finished within a few minutes, the recovery process would spend lots of time, decreasing the efficiency of the treatment.

Flow-through Catalytic Performance of Ag NPs@ SCOF Microspheres. By taking advantage of the microsized SCOF and the support of the Ag NPs to fabricate the Ag NPs@SCOF microspheres, we designed a continuous flow setup for flow-through catalytic reduction of 4-NP. Compared with the static experiment, in a typical experiment, a feed solution containing a certain concentration of 4-NP and $\mathrm{NaBH}_{4}$ was pumped through a PVC tube containing Ag NPs@ SCOF. The catalytic processes performed with fluxes varying from 150 to $4000 \mathrm{~L} \mathrm{~m}^{-2} \mathrm{~h}^{-1}$ (LMH) were monitored by a $\mathrm{UV}-$ vis spectrometer. As shown in Figure 5a, the characteristic 
a

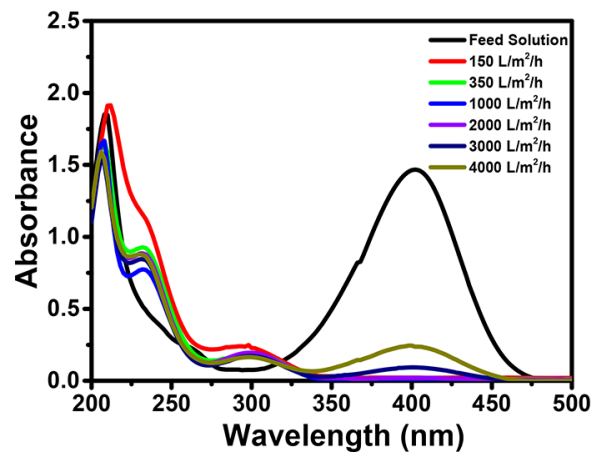

b

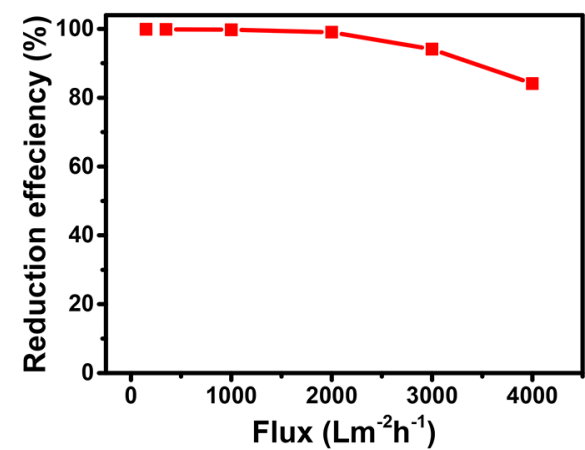

Figure 5. UV-vis spectra of the 4-NP solution in the flow-through system with a flux from 150 to $4000 \mathrm{LMH}$ (a), and the corresponding reduction efficiency (b).

Table 2. Comparison of the Catalytic Activities of Noble Metal-Based Heterogeneous Catalysts Reported Recently for 4-NP Reduction with $\mathrm{NaBH}_{4}$ under a Flow-through Process

\begin{tabular}{|c|c|c|c|c|c|}
\hline catalyst & $\begin{array}{c}\text { concentration of } \\
\text { 4-NP (mM) }\end{array}$ & $\begin{array}{l}\text { noble metal } \\
\text { content }(\mathrm{mg})\end{array}$ & $\begin{array}{l}\text { flow rate } \\
\text { (LMH) }\end{array}$ & $\begin{array}{l}\text { reduction efficiency } \\
(\%)\end{array}$ & ref. \\
\hline PET-DOPA-PEI-AuNPs & 0.30 & 0.44 & 40 & 99 & Chem. Eng. J., $2016^{54}$ \\
\hline Ag-PDA-IOs & 0.10 & 0.42 & 150 & 99 & ACS Appl. Mater. Interfaces, $\mathbf{2 0 1 6}^{79}$ \\
\hline NTEMs/PDA/Pd & 0.50 & & 34 & 80 & ACS Appl. Mater. Interfaces, $\mathbf{2 0 1 8}^{80}$ \\
\hline C-BCGO-Au-stc-M membrane & 0.27 & 0.96 & 87 & 96 & J. Hazard. Mater., $\mathbf{2 0 2 0}^{81}$ \\
\hline Ag NPs@SCOF & 0.11 & 0.53 & 2000 & 99 & this work \\
\hline
\end{tabular}
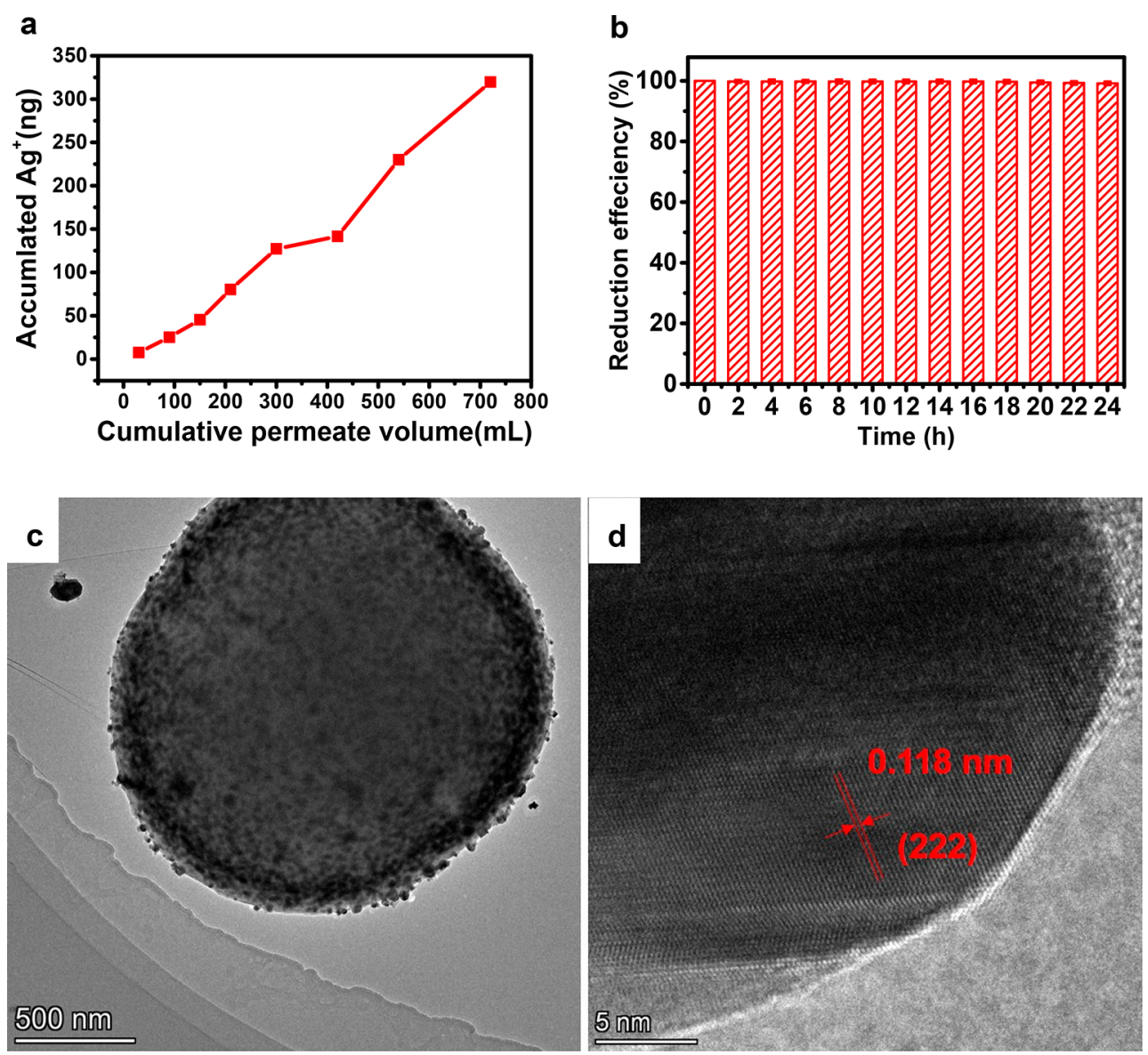

Figure 6. Release of Ag ions from the Ag NPs@SCOF microsphere in the flow-through system with a flux of 1000 LMH (a) and the corresponding reduction efficiency with prolonged reaction time (b). (c, d) TEM images of Ag NPs@SCOF microspheres after catalysis for 24 h. 
Scheme 2. Catalytic Mechanism Proposed for 4-NP Reduction with $\mathrm{NaBH}_{4}$ in the Presence of Ag NPs@SCOF Microspheres

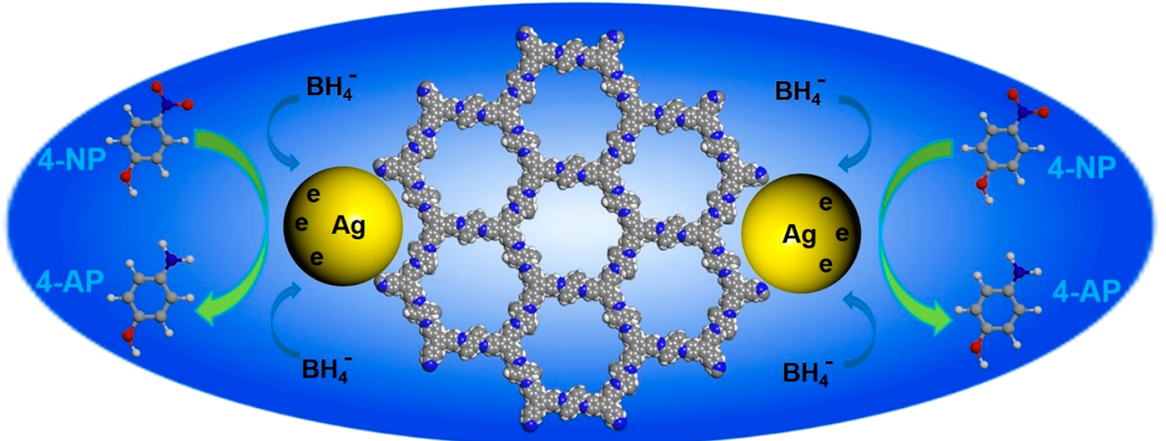

absorbance of 4-NP at $400 \mathrm{~nm}$ rapidly decreased to almost zero; correspondingly, the characteristic absorbance of the reduced product 4-AP increased at $300 \mathrm{~nm}$ as the feed solution flowed through the Ag NPs@SCOF microspheres under a flux of less than $2000 \mathrm{LMH}$. The reduction efficiency can be maintained at more than $99 \%$ as the flux increases from 150 to $2000 \mathrm{LMH}$ (Figure 5b). When the flux was higher than 2000 $\mathrm{LMH}$, a peak at $400 \mathrm{~nm}$ can be observed. The reduction efficiency decreased from $99 \%$ to $84 \%$ as the flux increased from $2000 \mathrm{LMH}$ to $4000 \mathrm{LMH}$. The higher the flux was, the greater the concentration of 4-NP became. The shorter residence time between the 4-NP solution and the Ag NPs@ SCOF microsphere decreased the reduction efficiency. ${ }^{99}$ Thus, the reduction efficiency and flux can be further optimized by increasing the concentration of catalysts. ${ }^{55}$

The reduction rate and reduction efficiency are two significant aspects for practical applications in organic pollutants treatment. Our fabricated Ag NPs@SCOF catalyst exhibited a better catalytic performance than the reported catalysts (Table 2). For example, Tripathi et al. fabricated flat membrane supported Au NPs and obtained an optimized flux of $40 \mathrm{LMH}$ with a reduction efficiency of $99 \%$ under flowthrough experiments. ${ }^{54}$ Compared with the flat sheet membrane, our prepared Ag NPs@SCOF microspheres had more advantages, such as loose structures and large specific surface areas, facilitating the fast and continuous catalytic treatment of organic pollutants.

Stability of Ag NPs@SCOF Microspheres. For practical applications, continuous flow-through catalytic reduction was carried out under a flux of $1000 \mathrm{LMH}$. The feed solution containing $15 \mathrm{mg} / \mathrm{L}$ 4-NP and $0.05 \mathrm{M} \mathrm{NaBH} \mathrm{N}_{4}$ was continuously pumped through a PVC tube containing $50 \mathrm{mg}$ of Ag NPs@SCOF microspheres. The catalytic processes and the concentrations of $\mathrm{Ag}$ ions in the filtrate were monitored by $\mathrm{UV}-$ vis spectrometry and ICP-MS, respectively. As shown in Figure 6a, the concentration of $\mathrm{Ag}$ ions in the filtrate linearly increased with prolonged time, and the concentration after testing for $24 \mathrm{~h}$ was calculated to be $4.3 \mathrm{ppb}$, which is much lower than the limit of Ag ions (100 ppb) in drinking water. ${ }^{82}$ Furthermore, the cumulative Ag ions in the filtrate after testing for $24 \mathrm{~h}$ was only $325 \mathrm{ng}$, which accounted for $0.07 \mathrm{wt} \%$ of the total Ag supported on the Ag NPs@SCOF microspheres. That is, more than 99.9 wt \% Ag NPs were maintained on the surface of the Ag NPs@SCOF microspheres. The excellent stability of our prepared Ag NPs@SCOF microsphere during the continuous catalytic process can be contributed to the strong interactions between Ag NPs and SCOF and the large size of the catalyst avoiding leaching out. ${ }^{41}$ Correspondingly, the reduction efficiency was maintained at more than $99 \%$ after testing for $24 \mathrm{~h}$ (Figure $6 \mathrm{~b}$ ). From the TEM images (Figure $6 \mathrm{c}, \mathrm{d})$, the morphology of the synthesized Ag NPs@SCOF microspheres was almost unchanged after testing for $24 \mathrm{~h}$. Moreover, the XRD pattern of the Ag NPs@SCOF microspheres was also unaltered after testing for $24 \mathrm{~h}$ (Figure S7). All these results reflected the good stability of our prepared $\mathrm{Ag}$ NPs@SCOF microspheres.

Catalytic Reduction Mechanism. A mechanism was proposed based on the good catalytic performance of the prepared Ag NPs@SCOF microspheres toward 4-NP with a high $k_{\text {app }}$ value $\left(1.06 \mathrm{~min}^{-1}\right) /$ TOF $\left(81.2 \mathrm{~h}^{-1}\right)$ achieved for the static experiments and high flux (2000 LMH)/high reduction efficiency (more than 99\%) achieved for the flow-through experiments. The main reason for the excellent catalytic performance can be attributed to the unique structure of the prepared catalyst. First, the SCOF was designed and functionalized with nitrogen groups, which can immobilize $\mathrm{Ag}$ ions and restrict the size of Ag NPs grown on the surface of the SCOF. Small Ag NPs can provide more catalytic sites than large Ag NPs for fast electron transfer from an electron donor $\left(\mathrm{NaBH}_{4}\right)$ to an electron acceptor (4-NP) to catalytically reduce 4-NP. Moreover, the large surface area of the SCOF supplies abundant sites for supporting Ag NPs. In addition, the SCOF, a good semiconductor, serves as a cocatalyst, providing basic sites that strengthen the electron transfer of the noble metal nanoparticles (much better than the conjugated microporous polymer substrate $\mathrm{e}^{77}$ and the montmorillonite substrate reported in our previous work; ${ }^{78}$ TOF, $17 \mathrm{~h}^{-1}$ and 13 $\mathrm{h}^{-1}$, respectively). ${ }^{57-60}$ Furthermore, Ag NPs@SCOF microspheres with a zeta potential of $-9.8 \mathrm{mV}$ more easily adsorb 4NP with a relatively more positive change than the product 4$\mathrm{AP}$, facilitating the acceleration of the catalytic reduction reaction and the detachment of 4-AP from the surface of catalysts to refresh the free active sites for the continuous flowthrough reaction (Scheme 2). ${ }^{43}$

\section{CONCLUSIONS}

In summary, a spherical COF with nitrogen groups was designed to provide basic sites for $\mathrm{Ag}$ ions, by which small $\mathrm{Ag}$ NPs were immobilized on the SCOF to form Ag NPs@SCOF microspheres with superior catalytic performance toward 4NP. A high $k_{\text {app }}$ value $\left(1.06 \mathrm{~min}^{-1}\right) /$ TOF $\left(81.2 \mathrm{~h}^{-1}\right)$ was achieved for the static experiments. A high flux (2000 LMH)/ high reduction efficiency (more than 99\%) was achieved for the flow-through experiments, which is far better than the reported results. Furthermore, only 0.07 wt.\% Ag NPs were released from the catalytic system under a continuous flow- 
through process for the $24 \mathrm{~h}$ test, reflecting the good stability of our prepared Ag NPs@SCOF microspheres. The excellent stability of our prepared Ag NPs@SCOF microspheres during the continuous catalytic process can be contributed to the strong interactions between Ag NPs and SCOF and the large size of the catalyst avoiding leach out. This work demonstrated the design and synthesis of a heterostructure used for catalytic application through the integration of small Ag NPs and a functionalized spherical COF, which can be extended to the fabrication of other functional catalysts based on the covalent organic framework supported nanostructured metal. We believe that our work will provide an efficient new material and applicable technology for the facile treatment of toxic organic pollutants.

\section{ASSOCIATED CONTENT}

\section{SI Supporting Information}

The Supporting Information is available free of charge at https://pubs.acs.org/doi/10.1021/acsami.0c20444.

Calibration curves of 4-NP, a lab-scale continuous filtration setup and Ag NPs@SCOF with cotton blocking the ends of the loaded polyvinyl chloride tube, TEM and EDX image of Ag NPs@SCOF microsphere, recyclability of Ag NPs@SCOF in the reduction of 4-NP, and photographs of synthesized samples (PDF)

\section{AUTHOR INFORMATION}

\section{Corresponding Authors}

Ning Wang - CAS Key Laboratory of Coastal Environmental Processes and Ecological Remediation, Research Center for Coastal Environmental Engineering and Technology of Shandong Province, Shandong Key Laboratory of Coastal Environmental Processes, YICCAS, Yantai Institute of Coastal Zone Research, Chinese Academy of Sciences, Yantai, Shandong 264003, P. R. China; Center for Ocean MegaScience, Chinese Academy of Sciences, Qingdao 266071, P. R. China; University of Chinese Academy of Sciences, Beijing 100049, P.R. China; 10 orcid.org/0000-0001-7590-7801; Phone: +86-535-2109237; Email: nwang@yic.ac.cn

Dawei Pan - CAS Key Laboratory of Coastal Environmental Processes and Ecological Remediation, Research Center for Coastal Environmental Engineering and Technology of Shandong Province, Shandong Key Laboratory of Coastal Environmental Processes, YICCAS, Yantai Institute of Coastal Zone Research, Chinese Academy of Sciences, Yantai, Shandong 264003, P. R. China; Center for Ocean MegaScience, Chinese Academy of Sciences, Qingdao 266071, P. R. China; University of Chinese Academy of Sciences, Beijing 100049, P.R. China; (1) orcid.org/0000-0002-6166-9707; Phone: +86-535-2109237; Email: dwpan@yic.ac.cn

\section{Authors}

Fushuai Wang - Yantai University, Yantai, Shandong 264005, P. R. China

Fei Pan - CAS Key Laboratory of Coastal Environmental Processes and Ecological Remediation, Research Center for Coastal Environmental Engineering and Technology of Shandong Province, Shandong Key Laboratory of Coastal Environmental Processes, YICCAS, Yantai Institute of Coastal Zone Research, Chinese Academy of Sciences, Yantai,
Shandong 264003, P. R. China

Shunyang Yu - CAS Key Laboratory of Coastal Environmental Processes and Ecological Remediation, Research Center for Coastal Environmental Engineering and Technology of Shandong Province, Shandong Key Laboratory of Coastal Environmental Processes, YICCAS, Yantai Institute of Coastal Zone Research, Chinese Academy of Sciences, Yantai, Shandong 264003, P. R. China; University of Chinese Academy of Sciences, Beijing 100049, P.R. China

Complete contact information is available at:

https://pubs.acs.org/10.1021/acsami.0c20444

\section{Author Contributions}

N.W., Writing-review and editing; F.W., writin--original draft; F.P., validation; S.Y., resources; and D.P., review and editing.

\section{Notes}

The authors declare no competing financial interest.

\section{ACKNOWLEDGMENTS}

The authors gratefully acknowledge the funding support from National Natural Science Foundation of China (No. 51903247), Key Science and Technology Program of Yantai City (No. 2018ZHGY075 and 2019XDHZ093), and Shandong Key Laboratory of Coastal Environmental Processes, YICCAS (Grant No. 2019SDHADKFJJ15).

\section{REFERENCES}

(1) Fu, Y.; Qin, L.; Huang, D.; Zeng, G.; Lai, C.; Li, B.; He, J.; Yi, H.; Zhang, M.; Cheng, M.; Wen, X. Chitosan Functionalized Activated Coke for Au Nanoparticles Anchoring: Green Synthesis and Catalytic Activities in Hydrogenation of Nitrophenols and Azo Dyes. Appl. Catal., B 2019, 255, 117740.

(2) Xiong, Z.; Zhang, H.; Zhang, W.; Lai, B.; Yao, G. Removal of Nitrophenols and Their Derivatives by Chemical Redox: A Review. Chem. Eng. J. 2019, 359, 13-31.

(3) Gong, W.; Wu, Q.; Jiang, G.; Li, G. Ultrafine Silver Nanoparticles Supported on a Covalent Carbazole Framework as High-Efficiency Nanocatalysts for Nitrophenol Reduction. J. Mater. Chem. A 2019, 7 (22), 13449-13454.

(4) Shen, J.; Zhou, Y.; Huang, J.; Zhu, Y.; Zhu, J.; Yang, X.; Chen, W.; Yao, Y.; Qian, S.; Jiang, H.; Li, C. In-Situ Sers Monitoring of Reaction Catalyzed by Multifunctional $\mathrm{Fe}_{3} \mathrm{O}_{4} @ \mathrm{TiO}_{2} @ \mathrm{Ag}$-Au Microspheres. Appl. Catal., B 2017, 205, 11-18.

(5) Zhang, P.; Wang, F.; Qin, Y.; Wang, N. Exfoliated Graphitic Carbon Nitride Nanosheets/Gold Nanoparticles/Spherical Montmorillonite Ternary Porous Heterostructures for the Degradation of Organic Dyes. ACS Appl. Nano Mater. 2020, 3 (8), 7847-7857.

(6) Yan, Z.; Fu, L.; Zuo, X.; Yang, H. Green Assembly of Stable and Uniform Silver Nanoparticles on 2D Silica Nanosheets for Catalytic Reduction of 4-Nitrophenol. Appl. Catal., B 2018, 226, 23-30.

(7) Ilgin, P.; Ozay, O.; Ozay, H. A Novel Hydrogel Containing Thioether Group as Selective Support Material for Preparation of Gold Nanoparticles: Synthesis and Catalytic Applications. Appl. Catal., B 2019, 241, 415-423.

(8) Yang, Y.; Jiang, K.; Guo, J.; Li, J.; Peng, X.; Hong, B.; Wang, X.; $\mathrm{Ge}, \mathrm{H}$. Facile Fabrication of $\mathrm{Au} / \mathrm{Fe}_{3} \mathrm{O}_{4}$ Nanocomposites as Excellent Nanocatalyst for Ultrafast Recyclable Reduction of 4-Nitropheol. Chem. Eng. J. 2020, 381, 122596.

(9) Yang, W.; Hu, W.; Zhang, J.; Wang, W.; Cai, R.; Pan, M.; Huang, C.; Chen, X.; Yan, B.; Zeng, H. Tannic Acid/Fe ${ }^{3+}$ Functionalized Magnetic Graphene Oxide Nanocomposite with High Loading of Silver Nanoparticles as Ultra-Efficient Catalyst and Disinfectant for Wastewater Treatment. Chem. Eng. J. 2021, 405, 126629. 
(10) You, J. G.; Shanmugam, C.; Liu, Y. W.; Yu, C. J.; Tseng, W. L. Boosting Catalytic Activity of Metal Nanoparticles for 4-Nitrophenol Reduction: Modification of Metal Naoparticles with Poly(Diallyldimethylammonium Chloride). J. Hazard. Mater. 2017, 324, 420-427.

(11) Wu, T.; Kou, Y.; Zheng, H.; Lu, J.; Kadasala, N. R.; Yang, S.; Guo, C.; Liu, Y.; Gao, M. A Novel $\mathrm{Au} @ \mathrm{Cu}_{2} \mathrm{O}-\mathrm{Ag}$ Ternary Nanocomposite with Highly Efficient Catalytic Performance: Towards Rapid Reduction of Methyl Orange Under Dark Condition. Nanomaterials 2019, 10 (1), 48 DOI: 10.3390/nano10010048.

(12) Qin, L.; Zeng, G.; Lai, C.; Huang, D.; Zhang, C.; Cheng, M.; Yi, H.; Liu, X.; Zhou, C.; Xiong, W.; et al. Synthetic Strategies and Application of Gold-based Nanocatalysts for Nitroaromatics Reduction. Sci. Total Environ. 2019, 652, 652-693.

(13) Pradhan, N.; Pal, A.; Pal, T. Silver Nanoparticle Catalyzed Reduction of Aromatic Nitro Compounds. Colloids Surf., A 2002, 196 (2-3), 247-257.

(14) Neal, R. D.; Inoue, Y.; Hughes, R. A.; Neretina, S. Catalytic Reduction of 4-Nitrophenol by Gold Catalysts: The Influence of Borohydride Concentration on the Induction Time. J. Phys. Chem. C 2019, 123 (20), 12894-12901.

(15) Wunder, S.; Polzer, F.; Lu, Y.; Mei, Y.; Ballauff, M. Kinetic Analysis of Catalytic Reduction of 4-Nitrophenol by Metallic Nanoparticles Immobilized in Spherical Polyelectrolyte Brushes. J. Phys. Chem. C 2010, 114 (19), 8814-8820.

(16) Esumi, K.; Isono, R.; Yoshimura, T. Preparation of PAMAMand PPI-metal (Silver, Platinum, and Palladium) Nanocomposites and their Catalytic Activities for Reduction of 4-Nitrophenol. Langmuir 2004, 20 (1), 237-243.

(17) Gao, D.; Li, S.; Wang, X.; Xi, L.; Lange, K. M.; Ma, X.; Lv, Y.; Yang, S.; Zhao, K.; Loussala, H. M.; Duan, A.; Zhang, X.; Chen, G. Ultrafine Ptru Nanoparticles Confined in Hierarchically Porous Carbon Derived from Micro-Mesoporous Zeolite for Enhanced Nitroarenes Reduction Performance. J. Catal. 2019, 370, 385-403.

(18) Qin, L.; Yi, H.; Zeng, G. M.; Lai, C.; Huang, D. L.; Xu, P. A.; Fu, Y. K.; He, J. F.; Li, B. S.; Zhang, C.; Cheng, M.; Wang, H.; Liu, X. G. Hierarchical Porous Carbon Material Restricted Au Catalyst for Highly Catalytic Reduction of Nitroaromatics. J. Hazard. Mater. 2019, $380,120864$.

(19) Xiao, F.; Ren, H.; Zhou, H.; Wang, H.; Wang, N.; Pan, D. Porous Montmorillonite@Graphene Oxide@Au Nanoparticle Composite Microspheres for Organic Dye Degradation. ACS Appl. Nano Mater. 2019, 2 (9), 5420-5429.

(20) Wang, D.; Duan, H.; Lu, J.; Lu, C. Fabrication of ThermoResponsive Polymer Functionalized Reduced Graphene Oxide@ $\mathrm{Fe}_{3} \mathrm{O}_{4} @ \mathrm{Au}$ Magnetic Nanocomposites for Enhanced Catalytic Applications. J. Mater. Chem. A 2017, 5, 5088-5097.

(21) Maham, M.; Nasrollahzadeh, M.; Sajadi, S. M.; Nekoei, M. Biosynthesis of $\mathrm{Ag} /$ Reduced Graphene Oxide $/ \mathrm{Fe}_{3} \mathrm{O}_{4}$ Using Lotus Garcinii Leaf Extract and Its Application as a Recyclable Nanocatalyst for the Reduction of 4-Nitrophenol and Organic Dyes. J. Colloid Interface Sci. 2017, 497, 33-42.

(22) Ye, W.; Yu, J.; Zhou, Y.; Gao, D.; Wang, D.; Wang, C.; Xue, D. Green Synthesis of Pt-Au Dendrimer-Like Nanoparticles Supported on Polydopamine-Functionalized Graphene and Their High Performance Toward 4-Nitrophenol Reduction. Appl. Catal., B 2016, 181, 371-378.

(23) Qin, L.; Huang, D.; Xu, P.; Zeng, G.; Lai, C.; Fu, Y.; Yi, H.; Li, B.; Zhang, C.; Cheng, M.; Zhou, C.; Wen, X. In-Situ Deposition of Gold Nanoparticles onto Polydopamine-Decorated g- $\mathrm{C}_{3} \mathrm{~N}_{4}$ for Highly Efficient Reduction of Nitroaromatics in Environmental Water Purification. J. Colloid Interface Sci. 2019, 534, 357-369.

(24) Nguyen, T. B.; Huang, C. P.; Doong, R. A. Enhanced Catalytic Reduction of Nitrophenols by Sodium Borohydride Over Highly RecyclableAu@Graphitic Carbon Nitride Nanocomposites. Appl. Catal., B 2019, 240, 337-347.

(25) Fu, Y.; Huang, T.; Jia, B.; Zhu, J.; Wang, X. Reduction of Nitrophenols to Aminophenols Under Concerted Catalysis by Au/g$\mathrm{C}_{3} \mathrm{~N}_{4}$ Contact System. Appl. Catal., B 2017, 202, 430-437.
(26) Zeng, G.; Huang, L.; Huang, Q.; Liu, M.; Xu, D.; Huang, H.; Yang, Z.; Deng, F.; Zhang, X.; Wei, Y. Rapid Synthesis of $\mathrm{MoS}_{2}$-PDA$\mathrm{Ag}$ Nanocomposites as Heterogeneous Catalysts and Antimicrobial Agents Via Microwave Irradiation. Appl. Surf. Sci. 2018, 459, 588595.

(27) Van Nguyen, C.; Lee, S.; Chung, Y. G.; Chiang, W. H.; Wu, K. C. W. Synergistic Effect of Metal-Organic Framework-Derived Boron and Nitrogen Heteroatom-Doped Three-Dimensional Porous Carbons for Precious-Metal-Free Catalytic Reduction of Nitroarenes. Appl. Catal., B 2019, 257, 117888.

(28) Gao, G.; Xi, Q.; Zhang, Y.; Jin, M.; Zhao, Y.; Wu, C.; Zhou, H.; Guo, P.; Xu, J. Atomic-Scale Engineering of Mof Array Confined Au Nanoclusters for Enhanced Heterogeneous Catalysis. Nanoscale 2019, 11 (3), 1169-1176.

(29) Deng, Z.; Guo, Y.; Li, Z.; Wang, X.; Peng, X.; Zeng, Y.-J. Ferrocenyl Metal-Organic Framework Hollow Microspheres for In Situ Loading Palladium Nanoparticles as a Heterogeneous Catalyst. Dalton T. 2019, 48 (24), 8995-9003.

(30) Ray, C.; Pal, T. Recent Advances of Metal-Metal Oxide Nanocomposites and their Tailored Nanostructures in Numerous Catalytic Applications. J. Mater. Chem. A 2017, 5 (20), 9465-9487.

(31) Wang, Q.; Astruc, D. State of the Art and Prospects in MetalOrganic Framework (MOF)-Based and MOF-Derived Nanocatalysis. Chem. Rev. 2020, 120 (2), 1438-1511.

(32) Lu, X. F.; Xia, B. Y.; Zang, S. Q.; Lou, X. W. Metal-Organic Frameworks Based Electrocatalysts for the Oxygen Reduction Reaction. Angew. Chem., Int. Ed. 2020, 59 (12), 4634-4650.

(33) Wang, R. L.; Li, D. P.; Wang, L. J.; Zhang, X.; Zhou, Z. Y.; Mu, J. L.; Su, Z. M. The Preparation of New Covalent Organic Framework Embedded with Silver Nanoparticles and its Applications in Degradation of Organic Pollutants from Waste Water. Dalton T. 2019, 48 (3), 1051-1059.

(34) Sharma, R. K.; Yadav, P.; Yadav, M.; Gupta, R.; Rana, P.; Srivastava, A.; Zbořil, R.; Varma, R. S.; Antonietti, M.; Gawande, M. B. Recent Development of Covalent Organic Frameworks (COFs): Synthesis and Catalytic (Organic-Electro-Photo) Applications. Mater. Horiz. 2020, 7 (2), 411-454.

(35) Iqbal, K.; Iqbal, A.; Kirillov, A. M.; Shan, C.; Liu, W.; Tang, Y. A New Multicomponent Cds/Ag@Mg-Al-Ce-Ldh Nanocatalyst for Highly Efficient Degradation of Organic Water Pollutants. J. Mater. Chem. A 2018, 6 (10), 4515-4524.

(36) Iqbal, K.; Iqbal, A.; Kirillov, A. M.; Wang, B.; Liu, W. S.; Tang, Y. New Ce-Doped Mgal-Ldh@Au Nanocatalyst for Highly Efficient Reductive Degradation of Organic Contaminants. J. Mater. Chem. A 2017, 5 (14), 6716-6724.

(37) Sun, Q.; Aguila, B.; Perman, J.; Earl, L. D.; Abney, C. W.; Cheng, Y.; Wei, H.; Nguyen, N.; Wojtas, L.; Ma, S. Postsynthetically Modified Covalent Organic Frameworks for Efficient and Effective Mercury Removal. J. Am. Chem. Soc. 2017, 139 (7), 2786-2793.

(38) Huang, N.; Zhai, L.; Xu, H.; Jiang, D. Stable Covalent Organic Frameworks for Exceptional Mercury Removal from Aqueous Solutions. J. Am. Chem. Soc. 2017, 139 (6), 2428-2434.

(39) Côté, A. P.; Benin, A. I.; Ockwig, N. W.; O’Keeffe, M.; Matzger, A. J.; Yaghi, O. M. Porous, Crystalline, Covalent Organic Frameworks. Science 2005, 310 (5751), 1166-1170.

(40) Waller, P. J.; Gándara, F.; Yaghi, O. M. Chemistry of Covalent Organic Frameworks. Acc. Chem. Res. 2015, 48 (12), 3053-3063.

(41) Wang, L.; Xu, H.; Qiu, Y.; Liu, X.; Huang, W.; Yan, N.; Qu, Z. Utilization of $\mathrm{Ag}$ Nanoparticles Anchored in Covalent Organic Frameworks for Mercury Removal from Acidic Waste Water. J. Hazard. Mater. 2020, 389, 121824.

(42) El-Kaderi, H. M.; Hunt, J. R.; Mendoza-Cortés, J. L.; Côté, A. P.; Taylor, R. E.; O'Keeffe, M.; Yaghi, O. M. Designed Synthesis of 3D Covalent Organic Frameworks. Science 2007, 316 (5822), 268272.

(43) Cao, H. L.; Liu, C.; Cai, F. Y.; Qiao, X. X.; Dichiara, A. B.; Tian, C.; Lü, J. In Situ Immobilization of Ultra-Fine Ag Nps onto Magnetic Ag@Rf@Fe $\mathrm{O}_{4}$ Core-Satellite Nanocomposites for The Rapid Catalytic Reduction of Nitrophenols. Water Res. 2020, 179, 115882. 
(44) Xia, T. T.; Liu, C. Z.; Hu, J. H.; Guo, C. Improved Performance of Immobilized Laccase on Amine-Functioned Magnetic $\mathrm{Fe}_{3} \mathrm{O}_{4}$ Nanoparticles Modified with Polyethylenimine. Chem. Eng. J. 2016, 295, 201-206.

(45) Chang, Y. C.; Chen, D. H. Catalytic Reduction of 4Nitrophenol by Magnetically Recoverable Au Nanocatalyst. J. Hazard. Mater. 2009, 165 (1), 664-669.

(46) Chen, Y.; Wu, T.; Xing, G.; Kou, Y.; Li, B.; Wang, X.; Gao, M.; Chen, L.; Wang, Y.; Yang, J.; et al. Fundamental Formation of ThreeDimensional $\mathrm{Fe}_{3} \mathrm{O}_{4}$ Microcrystals and Practical Application in Anchoring $\mathrm{Au}$ as Recoverable Catalyst for Effective Reduction of 4Nitrophenol. Ind. Eng. Chem. Res. 2019, 58, 15151-15161.

(47) Park, J.; Bae, S. Highly Efficient and Magnetically Recyclable Pd Catalyst Supported by Iron-Rich Fly Ash@Fly Ash-Derived $\mathrm{SiO}_{2}$ for Reduction of P-Nitrophenol. J. Hazard. Mater. 2019, 371, 72-82.

(48) Hou, C.; Zhao, D. Y.; Chen, W. Q.; Li, H.; Zhang, S. F.; Liang, C. Covalent Organic Framework-Functionalized Magnetic $\mathrm{CuFe}_{2} \mathrm{O}_{4} /$ $\mathrm{Ag}$ Nanoparticles for the Reduction of 4-Nitrophenol. Nanomaterials 2020, 10 (3), 426.

(49) Kou, Y.; Wu, T.; Zheng, H.; Kadasala, N. R.; Yang, S.; Guo, C.; Chen, L.; Liu, Y.; Yang, J. Recyclable Magnetic MIP-Based SERS Sensors for Selective, Sensitive, and Reliable Detection of Paclobutrazol Residues in Complex Environments. ACS Sustainable Chem. Eng. 2020, 8 (38), 14549-14556.

(50) Xu, Y.; Shi, X.; Hua, R.; Zhang, R.; Yao, Y.; Zhao, B.; Liu, T.; Zheng, J.; Lu, G. Remarkably Catalytic Activity in Reduction of 4Nitrophenol and Methylene Blue by $\mathrm{Fe}_{3} \mathrm{O}_{4} @ \mathrm{COF}$ Supported Noble Metal Nanoparticles. Appl. Catal., B 2020, 260, 118142.

(51) Wang, H.; Wang, N.; Wang, F.; Xiao, F.; Pan, D. Spherical Montmorillonite-Supported Molybdenum Disulfide Nanosheets as a Self-Sedimentary Catalyst for Organic Pollutants Removal. Sep. Purif. Technol. 2020, 251, 117346.

(52) Werber, J. R.; Osuji, C. O.; Elimelech, M. Materials for NextGeneration Desalination and Water Purification Membranes. Nat. Rev. Mater. 2016, 1 (5), 16018.

(53) Wang, J.; Wu, Z.; Li, T.; Ye, J.; Shen, L.; She, Z.; Liu, F. Catalytic PVDF Membrane for Continuous Reduction and Separation of P-Nitrophenol and Methylene Blue in Emulsified Oil Solution. Chem. Eng. J. 2018, 334, 579-586.

(54) Subair, R.; Tripathi, B. P.; Formanek, P.; Simon, F.; Uhlmann, P.; Stamm, M. Polydopamine Modified Membranes with in Situ Synthesized Gold Nanoparticles for Catalytic and Environmental Applications. Chem. Eng. J. 2016, 295, 358-369.

(55) Qi, L.; Zhang, K.; Qin, W.; Hu, Y. Highly Efficient FlowThrough Catalytic Reduction of Methylene Blue Using Silver Nanoparticles Functionalized Cotton. Chem. Eng. J. 2020, 388, 124252.

(56) Yao, B. J.; Li, J. T.; Huang, N.; Kan, J. L.; Qiao, L.; Ding, L. G.; Li, F.; Dong, Y. B. Pd NP-Loaded and Covalently Cross-Linked COF Membrane Microreactor for Aqueous CBs Dechlorination at Room Temperature. ACS Appl. Mater. Interfaces 2018, 10 (24), 2044820457.

(57) Zhang, C.; Cui, M.; Ren, J.; Xing, Y.; Li, N.; Zhao, H.; Liu, P.; Ji, X.; Li, M. Facile Synthesis of Novel Spherical Covalent Organic Frameworks Integrated with $\mathrm{Pt}$ Nanoparticles and Multiwalled Carbon Nanotubes as Electrochemical Probe for Tanshinol Drug Detection. Chem. Eng. J. 2020, 401, 126025.

(58) Ouyang, D.; Luo, K. L.; Ma, W. D.; Wu, J.; Li, J.; He, Y. T.; Cai, Z. W.; Lin, Z. A Spherical Covalent-Organic Framework for Enhancing Laser Desorption/Ionization Mass Spectrometry for Small Molecule Detection. Analyst 2020, 145 (8), 3125-3130.

(59) Liu, J. M.; Hao, J. L.; Yuan, X. Y.; Liu, H. L.; Fang, G. Z.; Wang, S. Spherical Covalent Organic Frameworks as Advanced Adsorbents for Preconcentration and Separation of Phenolic Endocrine Disruptors, Followed by High Performance Liquid Chromatography. RSC Adv. 2018, 8 (47), 26880-26887.

(60) Ma, W.; Zheng, Q.; He, Y.; Li, G.; Guo, W.; Lin, Z.; Zhang, L. Size-Controllable Synthesis of Uniform Spherical Covalent Organic Frameworks at Room Temperature for Highly Efficient and Selective
Enrichment of Hydrophobic Peptides. J. Am. Chem. Soc. 2019, 141 (45), 18271-18277.

(61) Liao, G.; Fang, J.; Li, Q.; Li, S.; Xu, Z.; Fang, B. Ag-Based Nanocomposites: Synthesis and Applications in Catalysis. Nanoscale 2019, 11 (15), 7062-7096.

(62) Wang, N.; Hu, Y.; Zhang, Z. Sustainable Catalytic Properties of Silver Nanoparticles Supported Montmorillonite for Highly Efficient Recyclable Reduction of Methylene Blue. Appl. Clay Sci. 2017, 150, $47-55$.

(63) Wang, N.; Xiao, F.; Zhang, J.; Zhou, H.; Qin, Y.; Pan, D. Spherical Montmorillonite-Supported Nano-Silver as a Self-Sedimentary Catalyst for Methylene Blue Removal. Appl. Clay Sci. 2019, 174, 146-151.

(64) Yang, J.; Pan, B.; Li, H.; Liao, S.; Zhang, D.; Wu, M.; Xing, B. Degradation of p-Nitrophenol on Biochars: Role of Persistent Free Radicals. Environ. Sci. Technol. 2016, 50 (2), 694-700.

(65) Subodh Prakash, K.; Masram, D. T. Silver Nanoparticles Immobilized Covalent Organic Microspheres for Hydrogenation of Nitroaromatics with Intriguing Catalytic Activity. ACS Appl. Polym. Mater. 2020, DOI: 10.1021/acsapm.0c01111.

(66) Liu, Y.; Zhang, Y. Y.; Kou, Q. W.; Wang, D. D.; Han, D. L.; Lu, Z. Y.; Chen, Y.; Chen, L.; Wang, Y. X.; Zhang, Y. J.; Yang, J. H.; Xing, $\mathrm{S}$. $\mathrm{Fe}_{3} \mathrm{O}_{4} / \mathrm{Au}$ Binary Nanocrystals: Facile Synthesis with Diverse Structure Evolution and Highly Efficient Catalytic Reduction with Cyclability Characteristics in 4-nitrophenol. Powder Technol. 2018, $338,26-35$.

(67) Zhang, P.; Shao, C.; Zhang, Z.; Zhang, M.; Mu, J.; Guo, Z.; Liu, Y. In Situ Assembly of Well-dispersed Ag Nanoparticles (AgNPs) on Electrospun Carbon Nanofibers (CNFs) for Catalytic Reduction of 4nitrophenol. Nanoscale 2011, 3 (8), 3357-3363.

(68) Song, Y.; Jiang, H.; Wang, B.; Kong, Y.; Chen, J. SilverIncorporated Mussel-Inspired Polydopamine Coatings on Mesoporous Silica as an Efficient Nanocatalyst and Antimicrobial Agent. ACS Appl. Mater. Interfaces 2018, 10 (2), 1792-1801.

(69) Qin, L.; Zeng, Z.; Zeng, G.; Lai, C.; Duan, A.; Xiao, R.; Huang, D.; Fu, Y.; Yi, H.; Li, B.; Liu, X.; Liu, S.; Zhang, M.; Jiang, D. Cooperative Catalytic Performance of Bimetallic Ni-Au Nanocatalyst for Highly Efficient Hydrogenation of Nitroaromatics and Corresponding Mechanism Insight. Appl. Catal., B 2019, 259, 118035.

(70) Lu, S.; Hu, Y.; Wan, S.; McCaffrey, R.; Jin, Y.; Gu, H.; Zhang, W. Synthesis of Ultrafine and Highly Dispersed Metal Nanoparticles Confined in a Thioether-Containing Covalent Organic Framework and Their Catalytic Applications. J. Am. Chem. Soc. 2017, 139 (47), 17082-17088.

(71) Das, R.; Sypu, V. S.; Paumo, H. K.; Bhaumik, M.; Maharaj, V.; Maity, A. Silver Decorated Magnetic Nanocomposite $\left(\mathrm{Fe}_{3} \mathrm{O}_{4} @ P p y-\right.$ $\mathrm{Maa} / \mathrm{Ag}$ ) as Highly Active Catalyst Towards Reduction of 4Nitrophenol and Toxic Organic Dyes. Appl. Catal., B 2019, 244, 546-558.

(72) Wang, J. G.; Hua, X.; Li, M.; Long, Y. T. Mussel-Inspired Polydopamine Functionalized Plasmonic Nanocomposites for SingleParticle Catalysis. ACS Appl. Mater. Interfaces 2017, 9 (3), 30163023.

(73) Vilian, A. T. E.; Choe, S. R.; Giribabu, K.; Jang, S. C.; Roh, C.; Huh, Y. S.; Han, Y. K. Pd Nanospheres Decorated Reduced Graphene Oxide with Multi-Functions: Highly Efficient Catalytic Reduction and Ultrasensitive Sensing of Hazardous 4-Nitrophenol Pollutant. J. Hazard. Mater. 2017, 333, 54-62.

(74) Bai, L.; Jiang, W.; Liu, M.; Wang, S.; Sang, M.; Xuan, S.; Gong, $\mathrm{X}$. General and Facile Method to Fabricate Yolk-like Structural Magnetic Nanocatalysts. ACS Sustainable Chem. Eng. 2018, 6 (7), $8274-8284$.

(75) Zhang, L.; Lu, H.; Chu, J.; Ma, J.; Fan, Y.; Wang, Z.; Ni, Y. Lignin-Directed Control of Silver Nanoparticles with Tunable Size in Porous Lignocellulose Hydrogels and their Application in Catalytic Reduction. ACS Sustainable Chem. Eng. 2020, 8 (33), 12655-12663.

(76) He, J.; Razzaque, S.; Jin, S.; Hussain, I.; Tan, B. Efficient Synthesis of Ultrafine Gold Nanoparticles with Tunable Sizes in a 
Hyper-Cross-Linked Polymer for Nitrophenol Reduction. ACS Appl. Nano Mater. 2019, 2 (1), 546-553.

(77) Cao, H. L.; Huang, H. B.; Chen, Z.; Karadeniz, B.; Lü, J.; Cao, R. Ultrafine Silver Nanoparticles Supported on a Conjugated Microporous Polymer as High-Performance Nanocatalysts for Nitrophenol Reduction. ACS Appl. Mater. Interfaces 2017, 9 (6), 52315236.

(78) Xiao, F.; Qin, Y.; Wang, N.; Pan, D. Towards Mass Production of Au Nanoparticles Supported on Montmorillonite Microspheres for Catalytic Reduction of 4-Nitrophenol. Appl. Clay Sci. 2018, 166, 7479.

(79) Choi, G. H.; Rhee, D. K.; Park, A. R.; Oh, M. J.; Hong, S.; Richardson, J. J.; Guo, J.; Caruso, F.; Yoo, P. J. Ag Nanoparticle/ Polydopamine-Coated Inverse Opals as Highly Efficient Catalytic Membranes. ACS Appl. Mater. Interfaces 2016, 8 (5), 3250-3257.

(80) Zeng, Z.; Wen, M.; Yu, B.; Ye, G.; Huo, X.; Lu, Y.; Chen, J. Polydopamine Induced In-Situ Formation of Metallic Nanoparticles in Confined Microchannels of Porous Membrane as Flexible Catalytic Reactor. ACS Appl. Mater. Interfaces 2018, 10 (17), 14735-14743.

(81) Zhong, Y.; Mahmud, S.; He, Z.; Yang, Y.; Zhang, Z.; Guo, F.; Chen, Z.; Xiong, Z.; Zhao, Y. Graphene Oxide Modified Membrane for Highly Efficient Wastewater Treatment by Dynamic Combination of Nanofiltration and Catalysis. J. Hazard. Mater. 2020, 397, 122774.

(82) Ratte, H. T. Bioaccumulation and Toxicity of Silver Compounds: A Review. Environ. Toxicol. Chem. 1999, 18 (1), 89108. 